\title{
Kognitivno-vedenjska obravnava debelosti pri otrocih in mladostnikih
}

\author{
Simona Klemenčič ${ }^{*}$ \\ Klinični oddelek za endokrinologijo, diabetes in bolezni presnove, Pediatrična klinika Ljubljana, \\ Univerzitetni klinični center Ljubljana
}

\begin{abstract}
Povzetek: Debelost in čezmerna telesna teža pri otrocih in mladostnikih sta povezani s številnimi bolezenskimi stanji, nižjo kakovostjo življenja, čustvenimi težavami in težavami v vrstniških odnosih. Pri razvoju debelosti ima poleg genetskega materiala in osebnostnih značilnosti posameznikov ključno vlogo tudi širše družbeno okolje, otrokova družina in starševski vzgojni slog. Zato so terapevtski ukrepi pri obravnavi debelosti pri otrocih navadno vezani na celotno družino in skoraj vedno je pri tem potrebno sodelovanje $z$ drugimi strokovnjaki, kot sta zdravnik in prehranski strokovnjak. V prispevku so predstavljena glavna načela kognitivno-vedenjske obravnave otrok z debelostjo ter najpogosteje uporabljene tehnike. Opisane tehnike naj bi bile del celostne individualne ali skupinske kognitivno-vedenjske terapije otroka s čezmerno telesno težo oz. debelostjo in njegove družine, nekatere pa so uporabne tudi posamezno in lahko veliko prispevajo h klasičnim oz. konservativnim programom za obravnavo debelosti. Pri mlajših otrocih se osredinimo predvsem na delo s starši in na vedenjske tehnike, medtem ko lahko pri mladostnikih že uporabljamo kognitivne tehnike, ki so bile razvite pretežno za odraslo populacijo.
\end{abstract}

Ključne besede: debelost, čustvene težave, otroci, starši, kognitivno-vedenjska terapija

\section{Cognitive-behavioural therapy in children and adolescents with obesity}

\author{
Simona Klemenčič \\ Clinical Department of Endocrinology, Diabetes and Metabolic Disease, Division of Paediatrics, \\ University Medical Centre Ljubljana, Slovenia
}

\begin{abstract}
Obesity and overweight in children and adolescents are associated with numerous health conditions, poorer quality of life, emotional and behavioural problems, and, moreover, with poorer peer relationships. In addition to an individual's genetic predispositions and their personal characteristics, the broader social environment, a child's family and the parents' parenting style play an important role in the development of obesity. Therefore, many therapeutic approaches to treating obesity in children target the whole family and almost always require a collaboration of a paediatrician and nutritionist. The article discusses the main principles of cognitive-behavioral therapy in children with obesity and the most commonly used techniques. The described techniques should be integrated in individual or group cognitive-behavioral therapy of an obese or overweight child and his or her family. Some of them can be used separately as a significant contribution to conservative approaches to treating childhood obesity. With young children, the focus should be placed mainly on behavioural techniques and work with parents, while many cognitive techniques designed for adult population can be applied in therapy with adolescents.
\end{abstract}

Keywords: obesity, emotional problems, children, parents, cognitive-behavioral therapy

\footnotetext{
*Naslov/Address: dr. Simona Klemenčič, Klinični oddelek za endokrinologijo, diabetes in bolezni presnove, Pediatrična klinika Ljubljana, Univerzitetni klinični center Ljubljana, Bohoričeva 20,1525 Ljubljana, e-mail: simona.klemencic@kclj.si
}

Članek je licenciran pod pogoji Creative Commons Attribution 4.0 International licence. (CC-BY licenca). The article is licensed under a Creative Commons Attribution 4.0 International License (CC-BY license). 


\section{Psihološki in zdravstveni vidiki debelosti pri otrocih}

Številne raziskave so ugotavljale povezanost med debelostjo ter čustvenimi in vedenjskimi težavami, kakovostjo življenja in socialnimi odnosi. Omenjena povezanost ima vzajemen vpliv, saj debelost lahko vpliva na pojav omenjenih težav, hkrati pa življenjske stiske otroka prispevajo k razvoju debelosti.

Pri otrocih s čezmerno telesno težo so opažali več depresivnih simptomov kot pri njihovih vrstnikih (Erermis idr., 2004; Sjoberg, Nilsson in Leppert, 2005), opažali so tudi večjo razširjenost drugih čustvenih, anksioznih in somatoformnih motenj, pri čemer so težave navadno nastale po pojavu debelosti (Britz idr., 2000; Goodman in Whitaker, 2002). Nadalje so ugotavljali nižjo kakovost življenja, kar se je odražalo predvsem v telesni oviranosti (Fallon idr., 2005; Schwimmer, Burwinkle in Varni, 2003), pa tudi na drugih področjih (pri akademski samopodobi in samopodobi, vezani na socialne odnose). Otroci, ki so debeli, se v večini počutijo neprivlačne, imajo negativno telesno samopodobo, nižje samospoštovanje oz. s svojim videzom niso zadovoljni, kar še posebej velja za dekleta (Stefanova, 2008; Strauss, 2000; Wang, 2001). Doživljajo veliko zbadanj vrstnikov, največkrat sošolcev, zaradi tega jih je sram, so osamljeni, žalostni, jezni in nemirni (Stefanova, 2008; Strauss, 2000). Zbadanje vrstnikov je pri otrocih povezano tako z nižjo samopodobo in samospoštovanjem kot tudi $\mathrm{s}$ povišano depresivno simptomatiko, razmišljanjem o samomoru in s poskusi samomora (Eisenberg, Neumark-Sztainer in Story, 2003).

Otroci $\mathrm{s}$ čezmerno telesno težo izkazujejo tudi več vedenjskih težav in simptomov, povezanih $\mathrm{z}$ motnjo hiperaktivnosti in nepozornosti, oboje pa naj bi pomembno prispevalo $\mathrm{k}$ nadaljnjemu pridobivanju telesne teže (Lam in Yang, 2007; McClure, Eddy, Kjellstrand, Snodgrass in Martinez, 2012; van Egmond-Froehlich idr., 2012). Predvideva se, da imajo posamezniki, ki so debeli, manjši inhibitorni nadzor, in sicer zaradi drugačnih nevrobioloških poti v možganih, natančneje zaradi manj učinkovitega izvršitvenega sistema ter okrepljenega sistema procesiranja nagrajevanih odzivov. Mladostniki, ki so bili predebeli, so bili v primerjavi z normalno težkimi vrstniki pri odločanju bistveno bolj nagnjeni k izbiri takojšnje nagrade ne glede na potencialne negativne posledice (Verdejo-Garcia idr., 2010).

Nadalje so mladostniki $\mathrm{z}$ nizko samopodobo in previsoko telesno težo bolj nagnjeni $\mathrm{k}$ tveganim vedenjem, kot sta kajenje in uživanje alkohola (Strauss, 2000). Dobra tretjina mladostnikov, ki poišče pomoč zaradi debelosti, poroča o epizodah kompulzivnega prenajedanja, vendar le redki dosežejo merila za diagnozo motnje kompulzivnega prenajedanja (Decaluwe, Braet in Fairburn, 2003).

Debelost pri otrocih se deloma povezuje tudi s spoznavnim razvojem: tako so imeli otroci s čezmerno telesno težo, stari med 8 in 16 let, v primerjavi s svojimi normalno težkimi vrstniki statistično pomembne nižje dosežke na številnih nevrokognitivnih področjih (spomin, psihomotorična hitrost, hitrost procesiranja informacij, reakcijski časi, pozornost, izvršitvene sposobnosti in kognitivna fleksibilnost), medtem ko niso opažali razlik v količniku splošne inteligentnosti (Bozkurt idr., 2016).
Ne nazadnje imajo otroci s čezmerno težo zdravstvene zaplete, s starostjo pa se tveganje zanje še povečuje. Med najpogostejšimi presnovnimi zapleti so sladkorna bolezen tipa 2, dislipidemija, ledvični zapleti, zamaščenost jeter in spremenjeno izločanje hormonov. Pomembni so tudi nepresnovni zapleti, kot je zmanjšana telesna zmožnost, in fitnes, ki povzroča še dodatno pridobivanje telesne teže, težave s kostmi, zvišan znotrajlobanjski tlak ter težave $z$ dihanjem, še posebno dihalni premori med spanjem puščajo dolgoročne posledice $\mathrm{v}$ centralnem živčnem sistemu in poškodujejo pljuča (Kotnik, 2017).

\section{Obravnava debelosti pri otrocih}

Poleg negativnega vpliva, ki ga ima debelost na posameznikovo življenje, debelost pri otrocih postaja vedno večji javnozdravstveni problem. Poleg nujno potrebnih družbenih ukrepov, ki so predvsem namenjeni preprečevanju debelosti, so ključnega pomena tudi ukrepi za otroke, ki že imajo čezmerno telesno težo oz. so debeli. Pediatrične smernice za obravnavo debelosti priporočajo prilagoditve življenjskega sloga, ki naj bi bile starosti in kulturnemu okolju prirejene, vključevale pa naj bi spremembe življenjskega sloga celotne družine (Styne idr., 2017).

Pri prehrani strokovnjaki predlagajo zmanjšanje hitre in predelane prehrane, zmanjšanje dodajanja namiznega sladkorja, koruznega sirupa, soli in maščobe, ukinitev sladkih pijač in uživanje celega sadja namesto sokov. Obroki naj bodo zmerni, redni in časovno razporejeni, odsvetujejo se dodatne porcije in prigrizki čez dan. Predlagajo tudi prepoznavanje sprožilcev za hranjenje pri otroku, kot je na primer dolgčas, stres, samota ali čas, preživet pred zasloni. Otroci naj pred zasloni (televizija, računalnik, tablica, telefon ...) ne bi preživeli več kot uro do dve na dan, če ne delajo za šolo. Telesno naj bi bili aktivni vsaj 20 minut dnevno, cilj pa naj bi bil 60 minut zmerne do intenzivne fizične aktivnosti na dan. Nadalje se priporoča spodbujanje zdravih spalnih vzorcev, da bi se preprečilo preveliko zaužitje kalorij (Styne idr., 2017).

Kot že omenjeno, ima velik pomen pri zdravljenju debelosti vključitev staršev in prilagoditev sprememb za celotno družino. Starši namreč v zgodnjem otroštvu precej določajo, kaj otrok poje, kdaj hrano zaužije in v kakšnem okolju, kasneje pa po modelnem učenju prenašajo na otroka odnos do hrane, sebe in gibanja (Golan, 2014). Tako se je debelost staršev izkazala kot največji napovedni dejavnik za debelost pri otrocih (Keane, Layte, Harrington, Kearney in Perry, 2012). Zato je pri obravnavi debelosti nujno vključiti celotno družino.

Nadalje ima velik pomen tudi vzgojni slog, saj sta tako popustljiv kot pretirano nadzirajoči slog vzgoje otrok pri hranjenju povezana $\mathrm{z}$ debelostjo pri otrocih, predvsem ker zmanjšata možnosti razvoja otrokove samoregulacije pri hrani (Moria in Rachel, 2011). Najmanj tveganja za debelost imajo otroci staršev s pozitivnim vzgojnim slogom, ki se odraža $\mathrm{v}$ tem, da so starši pozorni tako na njihove čustvene potrebe, vendar ob tem otrokom postavljajo jasno strukturo pri hranjenju, tako da zagotavljajo zdrave obroke in $\mathrm{z}$ različnimi alternativami. Takšni straši pozitivno krepijo zdrave prehranjevalne navade s pohvalami in spodbudami ter skrbijo, da je med obroki pozitivna socialna interakcija (Moria in 
Rachel, 2011). Velikega pomena je torej, da prepoznamo manj učinkovite vzgojne sloge in nezdrave vzorce komunikacije $\mathrm{v}$ družini. Starše poleg zdravih prehranjevalnih navad učimo tudi prijetnega vzdušja med obroki ter primerne komunikacije z otrokom, ki spodbuja rast otrokove samopodobe (Styne idr., 2017). Kadar terapevtski proces vključuje starše, ti prevzamejo aktivno vlogo v zdravljenju: spremenijo lastne navade, načrtno se spremljajo in opazujejo, načrtujejo obroke in dejavnosti. Starše spodbudimo, da vzpostavijo nagrajevalni sistem za otroka, ko doseže zastavljene cilje, pri čemer spodbujamo nagrade v obliki skupnega preživljanja časa ter takšne, ki promovirajo zdravje (družinski izleti, skupno kolesarjenje ali drsanje itd.).

\section{Psihoterapevtska obravnava debelosti pri otrocih}

Za otroke, ki imajo že zdravstvene ali psihološke posledice debelosti, ter njihove družine je smiselna psihoterapevtska obravnava, ki najpogosteje temelji na kognitivno-vedenjski terapiji. Posamezne kognitivno-vedenjske tehnike se lahko vključijo tudi v klasične programe za debelost, vendar naj bi bile praviloma del celostnega psihoterapevtskega procesa, $\mathrm{v}$ katerem terapevt presodi intenzivnost posameznih težav in določi prednostne naloge obravnave. Tako bo morda v primeru otroka $\mathrm{z}$ depresivno epizodo s samomorilnimi mislimi najprej potrebna obravnava le-te, ko pa bo težava obvladana, lahko začnemo obravnavo debelosti. Pri psihoterapevtski obravnavi debelosti naj bo posameznik vzporedno obravnavan pri zdravniku in prehranskem strokovnjaku, smiselna pa je tudi vključitev kinezioterapevta oz. strokovnjaka za telesno vadbo. Pri otrocih in mlajših mladostnikih $\mathrm{v}$ obravnavo praviloma vključujemo tudi starše, medtem ko se lahko starejši mladostniki v obravnavo vključijo samostojno.

Učinki psihoterapevtskih ukrepov pri obravnavi debelosti so do sedaj le delno opredeljeni. Poleg dokazane učinkovitosti vključevanja starševske in šolske podpore $\mathrm{v}$ zdravljenje debelosti (Bogle in Sykes, 2011; Golan, 2014) se kot ena od učinkovitejših kažejo načela kognitivno-vedenjske terapije. $\mathrm{V}$ metaanalitični raziskavi so se kognitivno-vedenjski ukrepi izkazali kot dokazano učinkoviti (good evidence based), s sicer nekoliko slabšo skladnostjo, a z zadovoljivim kliničnim učinkom. Najboljše rezultate so pokazali ukrepi, usmerjeni na spremembo življenjskega sloga, tako prehrane kot vadbe skupaj z vedenjsko-kognitivnimi komponentami (Peckmezian in Hay, 2017).

Brennan je s sodelavci preveril učinkovitost programa s 14 seansami, ki so temeljile na kognitivno-vedenjskih ukrepih življenjskega sloga pri mladostnikih s čezmerno telesno težo in debelostjo. Rezultati so pokazali, da so imeli udeleženi $\mathrm{v}$ programu po koncu programa pomembno izboljšano sestavo telesa, antropometrične meritve, kardiovaskularne parametre, prehrano in fizično aktivnost kot pred začetkom programa in $\mathrm{v}$ primerjavi $\mathrm{s}$ kontrolno skupino (Brennan, Walkley, Wilks, Fraser in Greenway, 2013). V program je bila vključena psihoedukacija, načrtovanje prehrane in fizične aktivnosti, skupno postavljanje ciljev, samonagrajevanje, prepoznavanje misli in čustev, povezanih s hranjenjem, oblikovanje pozitivnih strategij in izjav za soočanje s težkimi situacijami, asertivno komuniciranje, reševanje problemov in vzdrževanje spremembe. Program je bil časovno kratek (manj kot pol leta), dolgoročni izidi niso bili predstavljeni. Podobni rezultati so bili predstavljeni v pilotni raziskavi, kjer so ob vključitvi kognitivno-vedenjskih tehnik mladostniki izgubili telesno težo in izboljšali zdravstvene kazalce (Doughty, Njike in Katz, 2015).

\section{Kognitivno-vedenjska obravnava debelosti}

Jasne smernice za individualno ali skupinsko kognitivnovedenjsko obravnavo debelosti pri otrocih v doslej poznani literaturi še niso opredeljene. V nadaljevanju so zato izbrani in našteti najpogosteje zasledeni elementi obravnave in tehnike, ki so povzeti po uveljavljenih modelih kognitivno-vedenjske obravnave (Beck, 1995), po preverjenih in objavljenih programih (Brennan idr., 2013; Doughty idr., 2015) ter po smernicah in priporočilih za obravnavo debelosti (Beck, 2007; Beck in Beck Busis, 2015; Styne idr., 2017).

\section{Ocenjevanje}

$\mathrm{V}$ prvih srečanjih poleg osnovne psihološke ocene otrokovega čustvenega in vedenjskega delovanja terapevt natančno oceni prehranjevalne in gibalne navade, spanje ter časa, ki ga otrok preživi pred zasloni, ko ne dela za šolo (zaslonski čas). Terapevt poskuša prepoznati glavne predispozicijske, vzdrževalne in sprožilne dejavnike, ki so prispevali $\mathrm{k}$ razvoju in ohranjanju telesne teže, na podlagi katerih izdela konceptualizacijo. Vanjo vključi tudi varovalne dejavnike, ki so lahko v pomoč pri doslednem izvajanju ukrepov. Posebno je pozoren na kritične situacije, kjer otrok zaužije bodisi nezdravo hrano ali neprimerno količino hrane, otrokov odnos do svojih težav in lastnega telesa, motivacijo za spremembo, morebitno sopojavnost prenajedanja oz. kompulzivnega hranjenja, nočnega hranjenja ter zbadanja vrstnikov ali odraslih. Slednji dejavniki so v pomoč pri izdelavi funkcionalne analize vedenja. Pomembno je tudi ocenjevanje psihosocialnih komorbidnosti, tj. čustvenih in vedenjskih težav (še posebno depresije in samopoškodbenega vedenja), telesne in splošne samopodobe, izostajanja ali izogibanja šoli, socialne tesnobe, izbruhov jeze, motenj hranjenja, družinske dinamike in odnosa družine do debelosti, uporabe drog in alkohola ter spolne aktivnosti (Styne idr., 2017).

\section{Načrt obravnave}

Glede na otrokovo starost in druge lastnosti otroka in družine terapevt naredi načrt obravnave. Smiselni so tedenski razmiki med seansami, po potrebi se termini uskladijo $\mathrm{z}$ drugimi člani tima (zdravnikom, prehranskim ali športnim strokovnjakom). Mlajši kot je otrok, bolj načelo dela temelji na starših, pri starejših mladostnikih pa je lahko obravnava že pretežno individualna. Tudi pri slednjih v vsaj nekaterih srečanjih sodelujemo s starši, s čimer zagotavljamo njihovo podporo pri spremembi navade. Pozorni moramo biti pri uporabi tehnik, ki morajo biti prilagojene otrokovi starosti oz. zmožnostim staršev. Terapevt individualno presoja 
njihovo uporabnost in jih smiselno prilagaja posameznikom. Družine $\mathrm{z}$ mlajšimi otroki se navadno bolje odzovejo na vedenjske tehnike, medtem ko se pri starejših mladostnikih lahko že učinkovito uporabljajo kognitivne tehnike, ki so bile razvite pretežno za odraslo populacijo. Po koncu intenzivne obravnave se dogovorimo za spremljanje na daljše časovno obdobje, t. i. booster seanse.

\section{Psihoedukacija}

Osnovni cilj psihoedukacije je posameznikovo razumevanje, kako čustvovanje, mišljenje in vedenje lahko vplivajo na pridobivanje telesne teže. Hranjenje namreč ni avtomatski proces, saj posameznikovo mišljenje in čustvovanje znatno prispevata tako k vsebini kot h količini zaužite hrane. Otroku in družini v nadaljevanju razložimo pasti ekstremnega omejevanja pri hrani in prehitrega hujšanja ter osmislimo vzpostavitev zdravih življenjskih navad, ki jih je možno vzdrževati dolgoročno. Pojasnimo tudi glavna načela kognitivno-vedenjske obravnave, vlogo posameznika v obravnavi, načine dela in smisel domačih nalog.

\section{Postavitev ciljev v obravnavi}

Pri postavitvi ciljev smo pozorni na to, da postavljamo predvsem vedenjske cilje (npr. št. ur gibanja, vzpostavitev rednih obrokov, zmanjšanje prigrizkov oz. epizod prenajedanja, itd.) ter se manj posvečamo t. i. medicinskim ciljem, na primer zmanjšanju števila kilogramov. Podatki o telesni teži so nam sicer lahko v pomoč pri ocenjevanju, vendar smo bolj kot na konkretne številke pozorni na trend spreminjanja telesne teže. Predvsem moramo biti pozorni, da ne sledimo slepo posameznikovemu cilju, da izgubi veliko število kilogramov v kratkem času, temveč ga usmerjamo $\mathrm{v}$ razmislek k spremembi navad, ki se lahko dolgoročno obrestujejo. Še posebno pri otrocih, ki so še v obdobju aktivne rasti, bo morda uspeh nenapredovanje telesne teže ob vzpostavitvi novih zdravih življenjskih navad.

\section{Razvijanje motivacije za spremembo}

Razvijanje in ohranjanje motivacije za spremembo je eno od ključnih načel, saj je obvladovanje telesne teže dolgotrajen, če ne skoraj vseživljenjski proces. Veliko posameznikov po začetnem navdušenju lahko hitro vzpostavi stare navade, saj so te navadno močno ponotranjenje in imajo številne regulatorne funkcije. Pri razvijanju motivacije poskušamo, da tako otrok kot celotna družina izrazi svoje lastne razloge za spremembo. Terapevt jih pri tem usmerja k razmišljanju na različna življenjska področja, kjer se bo sprememba navad lahko pozitivno odražala, na primer na lažje udejstvovanje pri šolski telovadbi oz. na igrišču, lastne občutke ponosa, manjši sram v družbi, večjo gibljivost, izboljšanje zdravstvenih parametrov, več možnosti pri izbiri oblek in podobno. Prednosti spremembe naj bodo čim konkretnejše, največ učinka pa imajo, če se napišejo na motivacijske kartice. Oseba naj jih prebira vsakodnevno ter sproti menja in dopolnjuje (Beck in Beck Busis, 2015).

\section{Spremljanje in beleženje}

Načrtno spremljanje in beleženje obrokov, telesne aktivnosti, spalnih navad ali časa pred zasloni je lahko koristno, saj ponuja vpogled $\mathrm{v}$ resnično stanje in pogosto razkrije napačna prepričanja o tem, koliko otrok oz. družina resnično sledita priporočilom zdravega življenjskega sloga. Navadno se odločimo le za eno področje, ki se ga spremlja, najpogosteje za tisto, ki je najbolj problematično, kasneje se preide na več področij oz. na drugo področje. Večina otrok spremljanja ne zmore beležiti več kot nekaj dni, zato naj to nalogo prevzamejo starši, še posebno se odločimo za beleženje količin hrane. Glede na povzetek spremljanja in beleženja terapevt skupaj z družino oblikuje cilje, ki sledijo priporočilom zdravnika oz. prehranskega strokovnjaka, na primer vključitev zajtrka, če je bil ta prej izpuščen.

\section{Načrtovanje aktivnosti}

Glede na pediatrične smernice za obravnavo debelosti družino spodbudimo k povečanju otrokove telesne dejavnosti ter $\mathrm{k}$ aktivnejšemu preživljanju prostega časa celotne družine (Styne idr., 2017). Zmanjšanje sedečih aktivnosti z vključevanjem fizične aktivnosti se je izkazalo za učinkovit ukrep (Epstein, Paluch, Gordy in Dorn, 2000). Z družino ali mladostnikom razdelamo natančen načrt preživljanja prostega časa. Omejimo čas, ki naj bi ga otrok preživel pred zasloni, spodbujamo vključitev v organizirane športne dejavnosti in naredimo načrt preživljanja skupnega časa družine. Pozorni moramo biti, da ne zastavimo previsokih ciljev, saj lahko njihovo nedoseganje krepi otrokove občutke naučene nemoči, pretirana telesna vadba, ki je otrok ni vajen, pa se lahko odrazi tudi v fizičnih poškodbah. Če imamo možnost sodelovati s kineziologom oz. strokovnjakom za telesno vadbo, takšne ukrepe načrtujemo skupno z njim.

\section{Podpora pri spremembi prehranjevalnih navad}

Pri obravnavi debelosti je sprememba prehranjevalnih navad skoraj neizogibna. Kot že rečeno, je najbolje, da smernice za spremembe podasta zdravnik in prehranski strokovnjak. Prehranjevalne navade naj bi spremenila vsa družina, ne le otrok. Odgovornost za sestavo in količino hrane poskušamo prenesti predvsem na starše, otroke pa pridobimo v sodelovanje. Ključno je, da se nepriporočena hrana, kolikor je le mogoče, odstrani iz otrokovega okolja. Starše spodbudimo, da odstranijo sladke pijače, slaščice in slane prigrizke, jih ne kupujejo oz. skladiščijo doma. Prav tako jih spodbudimo h kuhanju in pripravi priporočenih količin hrane, da pripravljena hrana ne ostaja dosegljiva za dodatno postrežbo. Za dolgoročno vzdrževanje primerne telesne teže je smiselno, da je vsaj nekatera otrokova najljubša hrana $v$ primernih količinah in razmikih vključena $\mathrm{v}$ prehranski načrt, saj se tako bistveno poveča verjetnost, da bo otrok temu načrtu lahko sledil. 


\section{Prepoznava tveganih situacij}

Ne glede na stopnjo spodbude $\mathrm{v}$ okolju pa bo vsak otrok najverjetneje izpostavljen situacijam, kjer bo težje sledil začrtanim spremembam. Pomembna naloga terapevta je, da takšne situacije pomaga prepoznati. To so lahko praznovanja rojstnih dni, kjer je hrane v izobilju, dolgčas ali šolski stres, ki spodbudi k dodatnim priboljškom, ali slabo vreme, ki otroka oz. družino odvrne od telesne aktivnosti. Obravnava teh situacij in iskanje rešitev za njih so pomemben del terapije, ki se ga lahko nadgradi s tehnikami samonadzora oz. z vključevanjem motivacijskih kartic (Brennan, Walkley, Fraser, Greenway in Wilks, 2008).

\section{Učenje tehnik samonadzora}

Za najbolj tvegane situacije, kjer otrok najtežje vzpostavi samonadzor, je smiselno učenje tehnik samonadzora, kakršna je stop tehnika. V terapiji tvegano situacijo naprej dodobra razdelamo, nato skupaj $\mathrm{z}$ otrokom oblikujemo spodbudno misel, ki bi ga v tvegani situaciji motivirala. Misli navadno pridružimo še vidno predstavo doseženega cilja. Potem otroka spodbudimo, da si tvegano situacijo predstavlja $\mathrm{v}$ domišljiji. $\mathrm{V}$ trenutku, ko mora otrok vzpostaviti samonadzor, mu predlagamo, da si predstavlja velik znak stop ali glasno reče stop. Otrok naj nato globo vdihne in izdihne ter si pove spodbudno misel oz. si predstavlja cilj, ki bi ga rad dosegel. Zatem ga $\mathrm{v}$ domišljiji vodimo $\mathrm{k}$ preusmeritvi pozornosti na druga vedenja, ki smo jih prej skupaj določili. Vajo večkrat ponovimo $\mathrm{v}$ terapiji in spodbudimo prakticiranje doma.

\section{Prepoznava disfunkcionalnih prepričanj in kognitivna restrukturacija}

Negativne avtomatske misli in disfunkcionalna prepričanja pogostokrat ovirajo napredek pri obvladovanju telesne teže (Beck in Beck Busis, 2015). Pojavljajo se lahko v zelo različnih oblikah, nekatere so že kulturno pogojene. Otrok je na primer prepričan, da se hrani ne zmore upreti; da majhen priboljšek nič ne spremeni; da je treba pojesti vse, kar je ponujeno, saj kasneje podobne priložnosti ne bo itd. Podobna prepričanja imajo navadno tudi otrokovi starši. Otroku in staršem ponovno predstavimo kognitivno-vedenjski model, vezan na njihovo konkretno situacijo, da vidijo, kako konkretna misel vpliva na hranjenje oz. aktivnost. Disfunkcionalna prepričanja rekonstruiramo in predlagamo nov način razmišljanja.

\section{Uporaba spodbudnih misli}

Še posebno za tvegane situacije poskušamo prepoznati in spodbuditi $\mathrm{k}$ uporabi pozitivnih strategij soočanja (Brennan idr., 2008). Lahko so splošno zastavljene, na primer »Jaz zmorem!" ali »Uspelo mi bo!"«, vendar so bistveno učinkovitejše, če so specifične in vezane na specifično situacijo, kjer ima posameznik največ težav (Beck in Beck Busis, 2015). Takšen primer bi bil na primer: »Ne bom vzel dodatnega kosa torte na rojstnodnevni zabavi. Užitek v ustih bo trajal le nekaj minut, kasneje pa mi bo žal. Zelo si želim, da dosežem svoj cilj, zato bom šel ta čas raje na stranišče in počakal, da huda želja mine.» Takšne misli moramo navadno otrokom oz. družini pomagati oblikovati, vendar poskušamo, da jih na koncu s svojimi besedami napišejo na motivacijske kartice, ki naj bodo čim dostopnejše, še posebno takrat ko bo posameznik v skušnjavi. Posameznik jih tako lahko nalepi na hladilnik, ima na jedilni mizi, v denarnici, peresnici, šolski torbi ali shranjene na mobilnem telefonu.

\section{Obravnava lakote, želje in hrepenenja po hrani}

Večina posameznikov s čezmerno telesno težo ima težave pri razlikovanju resnične lakote (stanja, ko je želodec več ur prazen), želje po hrani (hranjenje, kadar je hrana na voljo, brez posebnega občutka lakote, na primer po zadostnem obroku) in hrepenenja po hrani (ang. craving) (Beck, 2007). Pri slednjem posameznik doživlja močno fiziološko in čustveno potrebo po hranjenju, ob tem navadno čuti napetost in neprijeten hrepeneč občutek v ustih ali telesu. Predvsem mladostnike v prvi vrsti učimo prepoznavati razliko med temi različnimi stanji, najučinkoviteje je, če za domačo nalogo beležijo svoja doživljanja v enem dnevu, in sicer preden začno jesti obrok, na sredini obroka, takoj po njem in 20 minut po njem. Na naslednji stopnji posameznike učimo povišati toleranco za občutek lakote, tako da z izpostavljanjem občutku lakote uvidijo, da ta povzroča manj neugodja, kot so si sprva predstavljali, in da so to nelagodje sposobni vzdržati toliko časa, da se navadno zmanjša. Ob zaznani želji po hranjenju posameznike učimo razmišljanja, da si priznajo željo po hrani, vendar se ji ne vdajo, če še ni čas za obrok. Podobno jih soočamo $z$ občutki hrepenenja, kjer namesto hranjenja opazujemo in ob tem beležimo, kaj se s hrepenenjem dogaja, ko se mu ne vdamo. Navadno najintenzivnejši neprijetni občutki trajajo nekaj minut, potem pa postopno pojenjajo. $\mathrm{V}$ vseh primerih posameznike učimo premostitvenih strategij, kot so preusmerjanje pozornosti na druge dejavnosti, pitje vode, zapustitev prostora, sproščanje, zavrženje ostankov hrane in uporabo spodbudnih misli. S takšnimi vedenjskimi eksperimenti poskušamo restrukturirati posameznikova disfunkcionalna prepričanja, povezana z lakoto in hranjenjem, katerih bistvo navadno je to, da je omenjene občutke mogoče preseči le s hranjenjem.

\section{Čuječe hranjenje}

Namen čuječega hranjenja je naučiti posameznike, da povečajo svojo ozaveščenost o procesu hranjenja, hkrati pa tudi o svojih občutkih in samovrednotenju ob tem. Cilj pri tem je, da se s povišano ozaveščenostjo zmanjša avtomatsko hranjenje, ki lahko vodi k prenajedanju. Omenjeni pristop se je izkazal za učinkovit pri skupini odraslih oseb s čezmerno težo ali debelostjo (Dalen idr., 2010) in je najverjetneje uporaben tudi pri mladostnikih. Četudi se $\mathrm{v}$ terapiji ne odločimo za celoten postopek učenja čuječega hranjenja, pa je pomembno, da poudarjamo osnovna načela ozaveščanja procesa hranjenja. Otrokom in družini svetujemo hranjenje sede za mizo, brez gledanja televizije, računalnikov ali drugih elektronskih naprav ter vzpostavljanje prijetnega vzdušja med hranjenjem. To še posebej velja za prigrizke in slaščice, ki jih posamezniki velikokrat zaužijejo hitro, brez dobrega zavedanja o tem, da so nekaj pojedli. 


\section{Trening soočanja s težavami in trening socialnih veščin}

Po potrebi v obravnavo vključimo tudi tehnike reševanja problemov ali trening socialnih veščin, še posebno če uvidimo, da ima otrok težave $z$ omenjenimi področji. Še posebno otroci, ki so deležni zbadanja vrstnikov, se težko znajdejo v vrstniških stikih in pri tem potrebujejo konkretne usmeritve in spodbudo. Otroke spodbujamo, da razmišljajo o svojih odzivih na vrstniške pripombe in jih učimo primernih odzivov, ki jih lahko $\mathrm{v}$ neprijetnih situacijah uporabijo. Učimo jih tudi uporabe asertivnih komunikacijskih strategij, še posebno kadar morajo izraziti svojo prošnjo ali zahtevo, ne ugoditi prošnji ali zahtevi drugega ali kadar rabijo pomoč (Brennan idr., 2008). Večina posameznikov pridobi tudi $\mathrm{z}$ vajo asertivnih odzivov v situacijah, ko jim je ponujena hrana in je ne želijo pojesti (npr. pri sorodnih). $Z$ igro vlog lahko vadimo besedne odzive posameznika in jih po potrebi tudi zapišemo, na primer: »Babica, res sem vesela, da si zame spekla zavitek, vendar ga trenutno ne želim pojesti, saj sledim novemu prehranskemu načrtu. Bi bilo mogoče, da bi mi ga en košček zavila za s sabo, da ga bom lahko pojedla jutri po kosilu? «

\section{Vzdrževanje spremembe in preventiva spodrsljajev}

Preden sklenemo terapevtsko obravnavo, posvetimo nekaj srečanj temu, kako bosta otrok in družina spremembe vzdrževala dolgoročno. Ponovno prepoznamo visoko tvegane situacije, ki bi lahko družino povrnile na stare neučinkovite vzorce delovanja. Naredimo načrt za obvladovanje teh situacij (Brennan idr., 2008).

\section{Ocena obravnave}

Ob koncu obravnave opravimo podrobno oceno. Otroka in družino vprašamo po tistih spremembah, ki so zanju najbolj ključne, in po dejavnikih, ki so k temu najbolj prispevali. Pri tem je pomembno, da krepimo njihov občutek lastne kompetentnosti terjih spodbudimo k uporabi najučinkovitejših tehnik in spretnosti v prihodnje. Skupaj opravimo pregled doseženih ciljev in prepoznamo prednosti in šibkosti zastavljenih načrtov. Ponovno se osredinimo predvsem na vedenjske spremembe, hkrati pa skupaj ocenimo fizične oz. medicinske rezultate. Pri otrocih, ki so imeli težave na čustvenem, vedenjskem ali socialnem področju, preverimo tudi ta vidik, pri čemer si lahko pomagamo $\mathrm{z}$ enakim psihodiagnostičnimi pripomočki, kot smo jih uporabili $\mathrm{v}$ diagnostičnem postopku. Pri predstavitvi rezultatov otroku in družini ohranjamo pozitivno naravnanost.

\section{Sklep}

V prispevku so predstavljeni različni vidiki problematike debelosti pri otrocih in kognitivno-vedenjske tehnike, ki so lahko uporabni $\mathrm{v}$ individualni ali skupinski obliki kognitivno-vedenjske obravnave debelosti. Pred začetkom terapevtskega procesa je dobro zaradi velike sopojavnosti čustvenih, vedenjskih, šolskih in vrstniških težav opraviti natančno oceno oziroma kliničnopsihološki pregled. Še enkrat velja posebej omeniti, da pri zdravljenju debelosti najboljše rezultate kažejo ukrepi, ki vključujejo kombinacijo sprememb življenjskega sloga skupaj $\mathrm{z}$ vedenjskopsihološkimi komponentami (Peckmezian in Hay, 2017), zato je zgolj samostojna psihoterapevska obravnava otrok, ki imajo težave $\mathrm{z}$ debelostjo, brez drugih strokovnjakov (zdravnika, prehranskega strokovnjaka in po možnosti še kinezioterapevta) vprašljiva. Kljub predlaganim metodam in smernicam za obravnavo, ki kažejo dobre kratkoročne učinke med trajanjem programov, dolgoročno obvladovanje debelosti zaradi svoje kompleksnosti še vedno ostaja trd oreh za strokovnjake različnih strok. Slednje nam odražajo tudi podatki o nizki dolgoročni učinkovitosti različnih posegov, med drugim tudi pri uporabi kognitivno-vedenjske terapije pri odraslih, kjer so udeleženci po koncu terapije ponovno pridobili telesno težo (Cooper idr., 2010). Kot kaže, bo v prihodnosti treba še dodatno združiti interdisciplinarna znanja za nadaljnji razvoj splošnih programov in smernic pa tudi protokolov vedenjsko-kognitivne terapije pri obvladovanju debelosti. Le takšen pristop $\mathrm{z}$ naknadnim znanstvenim ovrednotenjem lahko dolgoročno prispeva $\mathrm{k}$ najboljši razrešitvi problema obravnave debelosti pri otrocih.

\section{Literatura}

Beck, J. S. (1995). Cognitive therapy: basics and beyond. New York: The Guilford Pres.

Beck, J. S. (2007). The Beck diet solution. Birmingham, Alabama: Oxmoor House, Inc.

Beck, J. S. in Beck Busis, D. (2015). The diet trap solution. London: Hay Hause UK Ltd.

Bogle, V. in Sykes, C. (2011). Psychological interventions in the treatment of childhood obesity: what we know and need to find out. Journal of Health Psychology, 16(7), 997-1014.

Bozkurt, H., Özer, S., Yilmaz, R., Sönmezgöz, E., Kazanci, O., Erbaş, O. in Demir, O. (2017). Assessment of neurocognitive functions in children and adolescents with obesity. Applied Neuropsychology: Child, 6(4), 262-268.

Brennan, L., Walkley, J., Fraser, S. F., Greenway, K. in Wilks, R. (2008). Motivational interviewing and cognitive behaviour therapy in the treatment of adolescent overweight and obesity: study design and methodology. Contemporary Clinical Trials, 29(3), 359-375.

Brennan, L., Walkley, J., Wilks, R., Fraser, S. F. in Greenway, K. (2013). Physiological and behavioural outcomes of a randomised controlled trial of a cognitive behavioural lifestyle intervention for overweight and obese adolescents. Obesity Research \& Clinical Practice, 7(1), e23-41.

Britz, B., Siegfried, W., Ziegler, A., Lamertz, C., HerpertzDahlmann, B. M., Remschmidt, H., ... in Hebebrand, J. (2000). Rates of psychiatric disorders in a clinical study group of adolescents with extreme obesity and in obese adolescents ascertained via a population based study. International Journal of Obesity, 24(12), 1707-1714. 
Cooper, Z., Doll, H. A., Hawker, D. M., Byrne, S., Bonner, G., Eeley, E., ... in Fairburn, C. G. (2010). Testing a new cognitive behavioural treatment for obesity: A randomized controlled trial with three-year follow-up. Behaviour Research and Therapy, 48(8), 706-713.

Dalen, J., Smith, B. W., Shelley, B. M., Sloan, A. L., Leahigh, L. in Begay, D. (2010). Pilot study: mindful eating and living(MEAL): weight, eating behavior, and psychological outcomes associated with a mindfulness-based intervention for people with obesity. Complementary Therapies in Medicine, 18(6), 260-264.

Decaluwe, V., Braet, C. in Fairburn, C. G. (2003). Binge eating in obese children and adolescents. The International Journal of Eating Disorders, 33(1), 78-84.

Doughty, K. N., Njike, V. Y. in Katz, D. L. (2015). Effects of a cognitive-behavioral therapy-based immersion obesity treatment program for adolescents on weight, fitness, and cardiovascular risk factors: a pilot study. Childhood Obesity, 11(2), 215-218.

Eisenberg, M. E., Neumark-Sztainer, D. in Story, M. (2003). Associations of weight-based teasing and emotional well-being among adolescents. Archives of Pediatrics \& Adolescent Medicine, 157(8), 733-738.

Epstein, L. H., Paluch, R. A., Gordy, C. C. in Dorn, J. (2000). Decreasing sedentary behaviors in treating pediatric obesity. Archives of Pediatrics \& Adolescent Medicine, 154(3), 220-226.

Erermis, S., Cetin, N., Tamar, M., Bukusoglu, N., Akdeniz, F. in Goksen, D. (2004). Is obesity a risk factor for psychopathology among adolescents? Pediatrics International: Official Journal of the Japan Pediatric Society, 46(3), 296-301.

Fallon, E. M., Tanofsky-Kraff, M., Norman, A. C., McDuffie, J. R., Taylor, E. D., Cohen, M. L., ... in Yanovski, J. A. (2005). Health-related quality of life in overweight and nonoverweight black and white adolescents. The Journal of Pediatrics, 147(4), 443-450.

Golan, M. (2014). Parenting and management of pediatric obesity clinical insights: obesity and childhood. V K. R. Casazza in L. J. Hanks (ur.). Clinical insights: obesity and childhood (str. 39-56). London: Future Medicine Ltd.

Goodman, E. in Whitaker, R. C. (2002). A prospective study of the role of depression in the development and persistence of adolescent obesity. Pediatrics, 110(3), 497-504.

Keane, E., Layte, R., Harrington, J., Kearney, P. M. in Perry, I. J. (2012). Measured parental weight status and familial socio-economic status correlates with childhood overweight and obesity at age 9. PLoS One, 7(8), e43503.

Kotnik, P. (2017). Debelost in zapleti debelosti pri otrocih in mladostnikih. [Obesity and complications of obesity in children and adolescents]. Slovenska pediatrija, 24, $60-67$.

Lam, L. T. in Yang, L. (2007). Overweight/obesity and attention deficit and hyperactivity disorder tendency among adolescents in China. International Journal of Obesity, 31(4), 584-590.
McClure, H. H., Eddy, J. M., Kjellstrand, J. M., Snodgrass, J. J. in Martinez, C. R., Jr. (2012). Child and adolescent affective and behavioral distress and elevated adult body mass index. Child Psychiatry and Human Development, 43(6), 837-854.

Moria, G. in Rachel, B.-M. (2011). Self-regulation and the management of childhood obesity. Journal of Community Medicine \& Health Education, 1(2), 107.

Peckmezian, T. in Hay, P. (2017). A systematic review and narrative synthesis of interventions for uncomplicated obesity: weight loss, well-being and impact on eating disorders. Journal of Eating Disorders, 5, 15.

Schwimmer, J. B., Burwinkle, T. M. in Varni, J. W. (2003). Health-related quality of life of severely obese children and adolescents. JAMA, 289(14), 1813-1819.

Sjoberg, R. L., Nilsson, K. W. in Leppert, J. (2005). Obesity, shame, and depression in school-aged children: a population-based study. Pediatrics, 116(3), e389-392.

Stefanova, V. (2008). Doživljanje in stigmatizacija debelosti pri mladih: magistrsko delo. [Experiences and stigmatization of obesity in youth]. Ljubljana: Univerza v Ljubljani, Fakulteta za družbene vede.

Strauss, R. S. (2000). Childhood obesity and self-esteem. Pediatrics, 105(1), e15.

Styne, D. M., Arslanian, S. A., Connor, E. L., Farooqi, I. S., Murad, M. H., Silverstein, J. H. in Yanovski, J. A. (2017). Pediatric obesity-assessment, treatment, and prevention: an endocrine society clinical practice guideline. The Journal of Clinical Endocrinology and Metabolism, 102(3), 709-757.

van Egmond-Froehlich, A., Bullinger, M., Holl, R. W., Hoffmeister, U., Mann, R., Goldapp, C., ... in de Zwaan, M. (2012). The hyperactivity/inattention subscale of the Strengths and Difficulties Questionnaire predicts shortand long-term weight loss in overweight children and adolescents treated as outpatients. Obesity Facts, 5(6), 856-868.

Verdejo-Garcia, A., Perez-Exposito, M., Schmidt-Rio-Valle, J., Fernandez-Serrano, M. J., Cruz, F., Perez-Garcia, M., ... in Campoy, C. (2010). Selective alterations within executive functions in adolescents with excess weight. Obesity, 18(8), 1572-1578.

Wang, Y. (2001). Cross-national comparison of childhood obesity: the epidemic and the relationship between obesity and socioeconomic status. International Journal of Epidemiology, 30(5), 1129-1136. 